\title{
IN SITU GEL AS PLATFORM FOR KETOCONAZOLE SLOW RELEASE DOSAGE FORM
}

\author{
METHAQ HAMAD SABAR, IMAN SABAH JAAFAR*, MASAR BASIM MOHSIN MOHAMED
}

Department of Pharmaceutics, College of Pharmacy, University of Mustansiriyah, Baghdad, Iraq Email: pharm.eman.aldahan@unomustansiriyah.edu.iq

Received: 08 Jun 2018, Revised and Accepted: 29 Jun 2018

\begin{abstract}
Objective: The aim of this study was to formulate ketoconazole (keto) as oral floating in situ gel to slow the release of keto in the stomach.

Methods: Sodium alginate (Na alginate) was used as a primary polymer in the preparation of the in situ gel and was supported by the following polymers: guar gum (GG), hydroxypropyl methylcellulose (HPMC) K4M, K15M and carbapol 940 as viscosity enhancing agents. As a consequence, and to complete the gelation process of above formulations was by adding the calcium carbonate $\left(\mathrm{CaCO}_{3}\right)$. The in situ gels were investigated by the following tests: floating lag time, floating duration, viscosity, drug content, in vitro gelling studies and in vitro release study.

Results: The study showed that the faster release was obtained with F1 which contained Na alginate alone. Additionally, reduction in Na alginate concentration resulted in significant increase in drug release. It was also noted that the increase in GG (viscosity enhancing polymer) concentration resulted in non-significant decrease in percent drug release and the reduction in CaCO3 concentration led to significant increase in drug release. Moreover, the release of drug was also affected by grade of viscosity enhancing polymer, the faster release was observed with the formula which contained a polymer of low viscosity (HPMC K4M) and an opposite result was with the high viscosity polymer (HPMCK15M).
\end{abstract}

Conclusion: This study showed the formulation of $\mathrm{Na}$ alginate with $\mathrm{GG}$ and $\mathrm{CaCO}_{3}$, led to gain floating in situ gel and a sustained release of keto.

Keywords: Ketoconazole, In-situ floating gel, Sodium alginate, Guar gum, HPMCK4M, HPMCK15M

(C) 2018 The Authors. Published by Innovare Academic Sciences Pvt Ltd. This is an open access article under the CC BY license (http://creativecommons.org/licenses/by/4.0/) DOI: http://dx.doi.org/10.22159/ijap.2018v10i5.27849

\section{INTRODUCTION}

Recently, gastro retentive dosage forms (GDF) have been studied extensively by researchers due to their essential characteristic of staying in the stomach for prolonged period of time which enabled slowing and sustaining the release of the selected drug in the stomach [1]. Also, this distinctive characteristic of GDF helped in solving many problems were associated with pharmaceutical formulations such as the narrow window absorption of the upper part of the gastrointestinal tract, drugs with short half-lives, unstable drugs in the environments of lower segment of the gastrointestinal tract, drugs for local target activity in the upper region of gastric tract and the low solubility of specific drugs in the basic gastric $\mathrm{pH}$ [2].

The GDF can be prepared by different techniques such as the dosage of low density to gain floating delivery system or high density dosage form that retain the dosage form in the lower part of the stomach. Additionally, the GDF can be obtained by formulating an adhesion form to the stomach mucosa or in a different way by expansion the size of the formulation to delay the emptying from the upper part of gut or by using ion exchange resin to gain adherence to the stomach mucosa [3]. The in situ gel preparation is one of the GDF that provide a controllable drug release in the stomach. This preparation is gelled upon contact to the stomach content and floats on the stomach surface fluid due to the influence of excipients having a lower density than the stomach fluid [4]. These properties were as a guide for many researchers to develop formulations that increased the efficacy of many drugs such as Rajinikanth et al. who utilised amoxicillin as a model for in situ gelling and they found a better eradication of $\mathrm{H}$. pylori in comparison with amoxicillin suspension [5]. This was due to the prolonged release in the stomach. Also, Darekar et al. prepared in situ gel incorporated with levocitrizine dihdrochloride to gain a prolonged release and to control the allergy symptoms [6]. In this current study, we focused on keto due to its systemic importance in mycoses treatment as this drug is classified as a fungistatic. The antifungal mechanism is by inhibiting cytochrome P450 enzyme leading to block the demethylation of primary sterols of the fungal membrane. By the aid of this mechanism, a distortion of the membrane structure is followed to retard the fungus growth. Also, keto as antifungal is a broad spectrum, inhibits a plenty of grampositive bacteria and protozoa [7].
Also, it was reported that $90 \%$ of keto binds to plasma albumin and its elimination showed biphasic behaviour of $2 \mathrm{~h}$ and $8 \mathrm{~h}$ as initial and terminal half-lives respectively. Usually, keto is metabolised to an inactive metabolite in the liver as both the later and the unchanged form of a drug are excreted via the renal route [8].

Additionally, keto is formulated for oral route and its absorption increases at stomach low pH [9]. A part of our work novelty and according to our knowledge, no study has investigated and formulated keto as in situ gel. This study used advantage of the increasing solubility of keto at the low $\mathrm{pH}$ of stomach as this guarantees a better bioavailability due to the slow release by the in situ gel. Thus, many studies have been done in this work to explore the in situ gel of keto such as determination of keto content in different formulations. Also, the examination of the in vitro of both gelation and floating and this is followed by viscosity measurements. These studies were supported by studying the effect of different concentrations of $\mathrm{CaCO}_{3}$ as a crosslinking and gas generating agent and polymer to polymer ratio of both the $\mathrm{Na}$ alginate and GG. Additionally, the effect of addition of different grade of HPMC in the presence of $\mathrm{Na}$ alginate on the release of keto was studied too.

\section{MATERIALS AND METHODS}

\section{Materials}

Keto was purchased from (Shanghai Macklin Biochemicals Co. Ltd,. China), Na alginate and $\mathrm{CaCO}_{3}$ (Sinopharm Chemical Reagent Co., Ltd. China), GG (Samara Drug Industry, Iraq), HPMCK4M and HPMCK15M (Alladin Industrial Co., Shanghai, China), carbapol 940 (Himedia lab., India.), Methyl paraben and propyl paraben (BDH Ind., India).

\section{Methods}

\section{Keto preparation as floating in situ gel}

Different compositions of Keto formulations of floating in situ gel as shown in table 1 were prepared by a gradual addition of Na alginate to a specific portion of water at $100^{\circ} \mathrm{C}$. This helps to solubilise $\mathrm{Na}$ alginate with the aid of stirring by using hot plate magnetic stirrer. Then this followed by addition of GG and in a different beaker, the parabens were dissolved in another portion of water at $100{ }^{\circ} \mathrm{C}$. This 
followed by addition of keto to the contents after mixing of the two beakers with continuous stirring and cooling. After $15 \mathrm{~min}$ of keeping as a waiting period for the preparation, the $\mathrm{CaCO}_{3}$ was added with continuous stirring until a homogeneous dispersion was gained. This formulation was allowed to cool at room temperature with volume adjusting using water to $100 \mathrm{ml}$ [10].

Table 1: The composition of keto in situ floating gel different formulas

\begin{tabular}{|c|c|c|c|c|c|c|c|c|c|}
\hline $\begin{array}{l}\text { Formulation code } \\
\text { ingredient }(\mathrm{mg})\end{array}$ & F1 & F2 & F3 & F4 & F5 & F6 & F7 & F8 & F9 \\
\hline Keto & 2000 & 2000 & 2000 & 2000 & 2000 & 2000 & 2000 & 2000 & 2000 \\
\hline $\mathrm{Na}$ alginate & 2000 & 2000 & 1000 & 1000 & 2000 & 2000 & 2000 & 2000 & 2000 \\
\hline GG & --- & 500 & 500 & 500 & 500 & 1500 & --- & --- & --- \\
\hline $\mathrm{CaCO}_{3}$ & 1000 & 1000 & 1000 & 500 & 2000 & 2000 & 1000 & 1000 & 1000 \\
\hline Methyl paraben & 90 & 90 & 90 & 90 & 90 & 90 & 90 & 90 & 90 \\
\hline Propyl paraben & 10 & 10 & 10 & 10 & 10 & 10 & 10 & 10 & 10 \\
\hline HPMC k4 M & --- & --- & --- & --- & --- & --- & 500 & --- & ---- \\
\hline HPMC K 15 M & --- & --- & --- & --- & --- & --- & --- & 500 & ---- \\
\hline Carbapol 940 & ---- & --- & --- & --- & --- & --- & --- & ---- & 500 \\
\hline D. W (ml) up to & 100 & 100 & 100 & 100 & 100 & 100 & 100 & 100 & 100 \\
\hline
\end{tabular}

\section{Evaluation of prepared keto in situ floating gel}

\section{Physical appearance and $\mathrm{pH}$}

All formulations were screened to check the presence of foreign particles or not. Also, the $\mathrm{pH}$ of all formulations was measured using a digital calibrated $\mathrm{pH}$ meter [11].

\section{Determination of drug content}

By the aid of sonication, a dissolved in situ solution was obtained by adding $10 \mathrm{ml}$ of in situ solution to $0.1 \mathrm{~N}$ hydrochloric acid $(\mathrm{HCl})$ and then top up with $0.1 \mathrm{~N} \mathrm{HCL}$ to $100 \mathrm{ml}$. The keto content was measured by using UV-spectrophotometer (Shimadzu, Japan) at $\lambda_{\max } 270 \mathrm{~nm}$ and this needed a proper dilution using $0.1 \mathrm{~N} \mathrm{HCl}[6]$.

\section{In vitro gelation study}

The capability of in situ solution to gel was evaluated visually by pouring $10 \mathrm{ml}$ of the in situ solution to $100 \mathrm{ml}$ of $0.1 \mathrm{~N} \mathrm{HCl} \mathrm{(pH} \mathrm{1.2).}$ This was followed by watching and counting the time needed by in situ solution to be solid and for how long persisted intact where this technique was graded to 3 classes:

(+)-Dispersed quickly within few minutes once gelation occurred.

$(++)$-Persistent intact for $12 \mathrm{~h}$ after instant gelation.

(+++)-Persistent intact for more than $24 \mathrm{~h}$ after instant gelation [12].

\section{In vitro floating study}

This was executed in stagnant condition at $37^{\circ} \mathrm{C}$ by pouring $10 \mathrm{ml}$ of liquid formulations into $100 \mathrm{ml}$ of $0.1 \mathrm{~N}$ HCL contained in a beaker.

This study assisted to evaluate firstly, the floating lag time which indicates the actual time for the gelling formulation to rise to the surface of media and secondly, the duration of floating which represents the period of floatation persistence [13].

\section{Viscosity measurement of the In-situ gelling solutions}

Viscosity of the solutions of in situ gels was determined using a Brookfield digital viscometer. $50 \mathrm{ml}$ of prepared solutions were sheared ata rate of $100 \mathrm{rpm} / \mathrm{min}$ using spindle number 2 at room temperature [14].

\section{In vitro release study}

To evaluate the release of keto from in situ gel, $10 \mathrm{ml}$ of in situ liquid was added to $900 \mathrm{ml}$ of $0.1 \mathrm{~N} \mathrm{HCl} \mathrm{(pH} \mathrm{1.2)} \mathrm{as} \mathrm{this} \mathrm{study} \mathrm{was} \mathrm{run} \mathrm{at} 37$ ${ }^{\circ} \mathrm{C}$ (body temperature) and stirring rate was $50 \mathrm{rpm}$ to mimic the mild agitation of stomach and keeping formulation solid by using type II (paddle method) dissolution apparatus. A withdrawn sample of $5 \mathrm{ml}$ was replaced by the same volume of fresh $0.1 \mathrm{~N}$ HCL to keep the sink condition within time course of the study and filtered by Whatman filter paper. These samples were diluted then keto quantified at $\lambda_{\max } 270 \mathrm{~nm}$ [15].

\section{Statistical analysis}

ANOVA test (one way analysis of the variance) was applied for statistical analysis. Significant statistical differences were considered when $(\mathrm{p}<0.05)$.

\section{RESULTS AND DISSCUSSION}

\section{Evaluation of ket floating in-situ gel}

In this current study, the formulations that contained keto for floating in situ gel were nine composed of $\mathrm{Na}$ alginate which is the main polymer that form gels. Additionally, GG, HPMC K4M, HPMC K15M and carbapol 940 were added to the solution of $\mathrm{Na}$ alginate to enhance its viscosity and to retard the release of keto upon gelation. Furthermore and to complete the gelation process, $\mathrm{CaCO}_{3}$ was added which also act as a gas generating agent. The last one was used in different concentrations to optimise the concentration for better gelation. Different parameters were investigated for formulations (F1to F9) as demonstrated in table 2 and discussed in details below.

Table 2: Evaluation of keto floating in-situ gel

\begin{tabular}{|c|c|c|c|c|c|c|}
\hline Formulation code & pH & $\begin{array}{l}\text { Gelation time } \\
\text { (sec) }\end{array}$ & Drug content & Floating lag time (sec) & $\begin{array}{l}\text { Duration of floating } \\
\text { (h) }\end{array}$ & Viscosity (cp) \\
\hline F1 & 7.5 & ++ & $93.8 \pm 0.43$ & $130 \pm 0.15$ & $>12$ & $336 \pm 0.33$ \\
\hline $\mathrm{F} 2$ & 7.75 & +++ & $94.3 \pm 0.23$ & $138 \pm 0.19$ & $>12$ & $678 \pm 0.56$ \\
\hline F3 & 8.81 & +++ & $95.1 \pm 0.17$ & $131 \pm 0.09$ & $>12$ & $473 \pm 0.3$ \\
\hline $\mathrm{F} 4$ & 8.81 & +++ & $92.33 \pm 0.1$ & $139 \pm 0.13$ & $>12$ & $538 \pm 0.14$ \\
\hline F5 & 7.79 & +++ & $89.5 \pm 0.36$ & $145 \pm 0.05$ & $>12$ & $574 \pm 0.26$ \\
\hline F6 & 8.34 & +++ & $95 \pm 0.3$ & $157 \pm 0.2$ & $>12$ & $1360 \pm 0.1$ \\
\hline F7 & 8.1 & +++ & $90.9 \pm 0.21$ & $133 \pm 0.2$ & $>12$ & $450 \pm 0.0 .5$ \\
\hline F8 & 8.2 & +++ & $89.1 \pm 0.4$ & $132 \pm 0.26$ & $>12$ & $511 \pm 0.22$ \\
\hline F9 & --- & --- & --- & --- & --- & $1515 \pm 0.4$ \\
\hline
\end{tabular}

$($ mean $\pm S D, n=3)$ 


\section{Physical appearance and $\mathrm{pH}$}

The nine formulations appearance was screened and found that all the liquid formulations were light brown, smooth and free from lumps or clots.

Also, the $\mathrm{pH}$ was investigated to make sure that the formulation $\mathrm{pH}$ is far from acidic or basic $\mathrm{pH}$ that harms the throat [16]. As shown in table 2, the pH of the eight formulations was within this range (7.758.81) which indicts a neutral or light alkaline $\mathrm{pH}$ and this is compatible with desired $\mathrm{pH}$ for oral formulations as no need for further $\mathrm{pH}$ adjustment [17].

\section{In vitro gelation time}

The process of gelation starts after the $\mathrm{CaCO}_{3}$ in liquid formulations being in contact with the acidic medium which is then followed by the release of gas and calcium ions. An instantaneous hardening to the liquid formulation occurs once the interaction happens between calcium ions and sodium alginate (the anionic polymer) giving a reservoir of three dimensional (3D) solid structure that slows the release of keto [18]. This was shown in table 2 where the gelation time study was executed using $0.1 \mathrm{~N} \mathrm{HCl}(\mathrm{pH} 1.2)$. The results revealed that all formulations showed an instant gelation and staying as an intact 3D structure for more than $24 \mathrm{~h}$ except the F1 that gelled instantly but remained intact not more than $12 \mathrm{~h}$. This could be explained that F1 composed of just $\mathrm{Na}$ alginate and free from viscosity enhancing agent, thus F1 showed rapid vanishing and this might be owing to the $\mathrm{Na}$ alginate gel is a porous scaffold. Obviously, this scaffold permits an ease water entrance leads to speed up the gel dissolution [19].

\section{Drug content}

The uniform distribution of keto in the formulations was studied as shown in table 2 and it was found that the drug content within this range (89.1-95.1\%). This was within the acceptable limits that are determined by USP (not $<85 \%$ and not $>115 \%$ ) [20].

\section{In vitro floating study}

The buoyancy of the in situ gels is due to the presence of $\mathrm{CaCO}_{3}$ which generates gas upon contact with the acidic medium which helps gels to float [21], and as the residence time of gels increased as this guarantees the absorption of drug in the stomach [22,23]. This was investigated via in vitro study as shown in table 2. All formulations floated for more than $12 \mathrm{~h}$ and the longest floating period was 157 seconds for F6 whereas F1 showed the least floating time which was 130 seconds.

\section{Viscosity study}

The liquid gels formulations that contained the viscosity enhancing agent helps to gain an appropriate viscosity and permit an easy swallowing. Also, as these agents facilitate the solid gels formulations to be coherent and solid enough to slow the release of keto.

The results of viscosity for formulations F1 to F9 were demonstrated in table 2 as F1 showed the lowest viscosity value $336 \mathrm{cp}$ and this might be due to the F1 contained no viscosity enhancing agents. On the other hand, the F9 showed the highest viscosity value $1515 \mathrm{cp}$ and this high value could be as a result of the presence of the carbapol 940 . This made F9 non pourable and no further investigation was followed this study on F9. Generally, the formulation's viscosity showed the following order $\mathrm{F} 9>\mathrm{F} 5>\mathrm{F} 8>\mathrm{F} 7$ that contained carbapol 940, GG, HPMCK15M and HPMCK4M respectively. Besides the impact of GG on the viscosity of in situ gels, increasing its concentration led to increase the viscosity of F5 and F6 and this might be as a result of the increase in the interaction amongst the polymers [24].

Also, it was noticed that the increase in the molecular weight of HPMC led to increase in the viscosity of the formulations as shown in F7 and F8. Another finding was the increase in $\mathrm{CaCO}_{3}$ concentration led to increase in the viscosity and this might be due to the increase in the dispersed amount of $\mathrm{CaCO} 3$ through the whole formula which helped in more hardening to the Na alginate gels [25].

\section{In vitro release study}

The release of keto was studied for $3 \mathrm{~h}$ for different formulations using USP paddle type apparatus. The keto concentration was calculated by the following equation of the calibration curve $(y=2.43 x+0.0341)$ which was constructed from serial dilutions of keto in $0.1 \mathrm{~N} \mathrm{HCl}$ solution ( $\mathrm{pH}$ 1.2). These dilutions were read by spectrophotometer at $\lambda$ max of keto which was $270 \mathrm{~nm}$. The main polymer in this work is the $\mathrm{Na}$ alginate, thus the effect of different amounts of the main polymer was investigated using F1, F2 and F3 and it was found as shown in fig. 1, the F1 released $99 \%(\mathrm{w} / \mathrm{w}$ ) of keto within $30 \mathrm{~min}$. This fast release referred to the low viscosity of F1and probably due to the lack of GG which in turn reflected the low solidity of the formulation upon gelation. As well and in the presence of $0.5 \%(\mathrm{w} / \mathrm{w})$ of $\mathrm{GG}$, a significant increase $(\mathrm{p}<0.05)$ in the release of keto was observed as the amount of $\mathrm{Na}$ alginate was reduced from $2 \%(\mathrm{w} / \mathrm{w})$ (F2 around $49 \%$ ) to $1 \%$ $(\mathrm{w} / \mathrm{w})(\mathrm{F} 3$ around $58 \%)$ and as shown in fig. 1. This result was similar to the preparation of ranitidine in situ gels by Rohith et al. study as they increased the Na alginate concentration from $0.5 \%(\mathrm{w} / \mathrm{w})$ to $1 \%$ $(\mathrm{w} / \mathrm{w})$, the release of ranitidine decreased from $96.5 \%$ to $74 \%$ within a frame time of $8 \mathrm{~h}$ respectively [26].

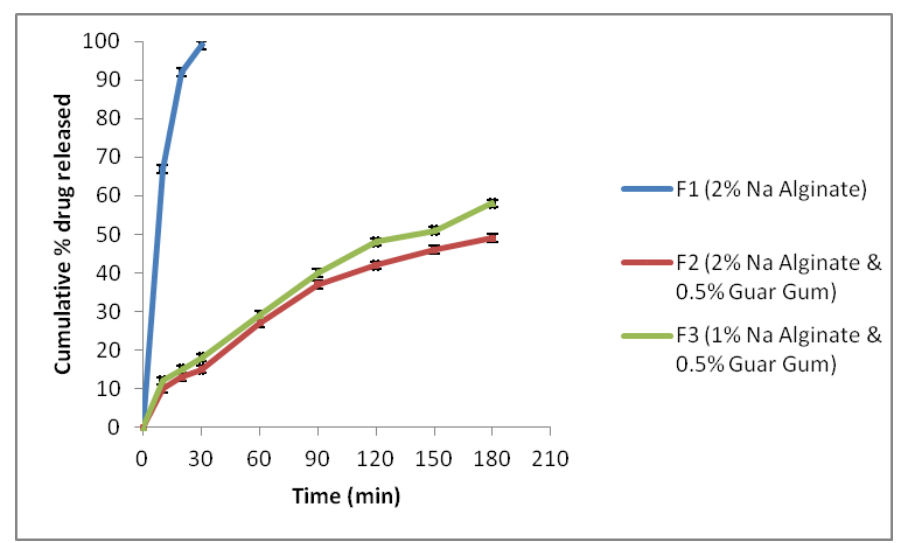

Fig. 1: Effect of Na alginate concentration on drug release (mean $\pm S D, n=3$ )

The effect of GG content was also studied as shown in fig. 2 and it was found a non-significant ( $p>0.05$ ) decrease in the keto release of F5a $43 \%$ compared with $40 \%$ of F6after 180 min as changes in the concentrations of GG was $0.5 \%(\mathrm{w} / \mathrm{w})$ and $1.5 \%(\mathrm{w} / \mathrm{w})$ respectively. The role of the presence of another polymer besides the main polymer in the formulation of in situ gels was investigated by
Maheswaran et al. They also found as they increased the HPMC content in $\mathrm{Na}$ alginate formulations as the release of diltiazem decreased [27]. This could be clarified that the presence of two polymers leads to increase the density of gelled formulations which consequently slows the diffusing molecule through this kind of matrix [24]. 


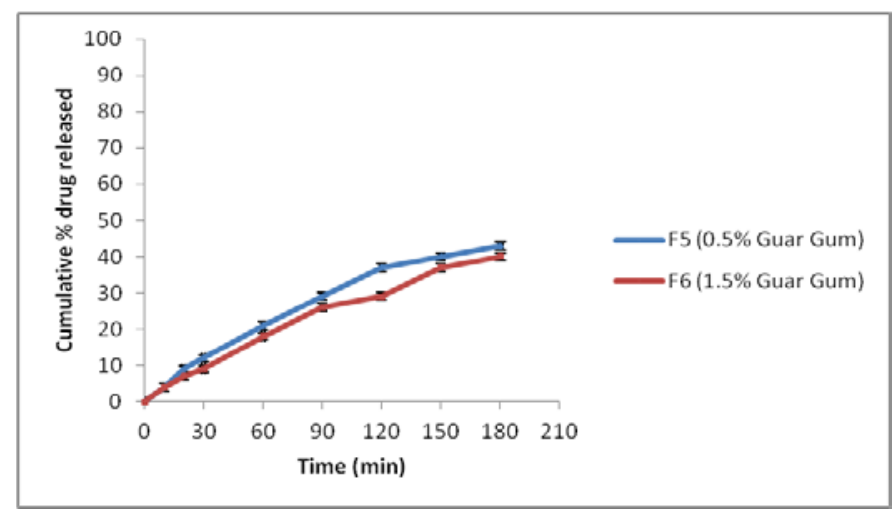

Fig. 2: Effect of GG concentration on drug release (mean $\pm S D, n=3$ )

Additionally and it was obvious the importance of $\mathrm{CaCO}_{3}$ in the gelation of $\mathrm{Na}$ alginate, hence the different contents of $\mathrm{CaCO}_{3}$ were investigated in F3 and F4. As shown in fig. 3, the release of keto decreased from $62 \%$ to $58 \%$ as the $\mathrm{CaCO}_{3}$ increased from $0.5 \%$ (w/w) to $1 \%(\mathrm{w} / \mathrm{w})$ in $\mathrm{F} 4$ and $\mathrm{F} 3$ respectively. This could be made clear that the increase in the calcium ions due to the increase in the $\mathrm{CaCO}_{3}$ content enhances sufficient crosslinking sites between sodium alginate molecules [28].

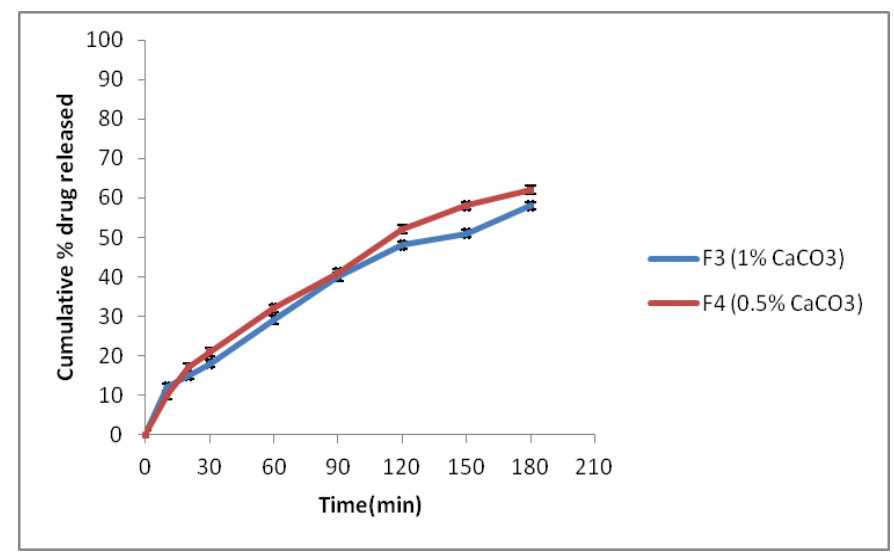

Fig. 3: Effect of $\mathrm{CaCO}_{3}$ concentration on drug release (mean $\pm \mathrm{SD}, \mathrm{n}=3$ )

The clear impact of GG in retarding the keto release from Na alginate formulations was encouraging to investigate other polymers as viscosity enhancing polymers. This was done by choosing a base formulation containing $2 \%(\mathrm{w} / \mathrm{w}) \mathrm{Na}$ alginate, $0.5 \%(\mathrm{w} / \mathrm{w}) \mathrm{GG}$ as in $\mathrm{F} 5$, further to, selective polymers the HPMC K4M and the HPMC K15Mwere added as in F7 and F8 respectively. As shown in fig. 4, the slow release order of these formulations was in the following order $\mathrm{F} 5>\mathrm{F} 8>\mathrm{F} 7$ and significant $(\mathrm{p}<0.05)$ decrease in the release rate of keto as F5 compared with F8 and F8 compared with F7. This could be clarified on the base of the effect of polymer grade of HPMC on the release of keto which was observable and showed an inverse relationship. As well, Li et al. obtained the same finding and they found the high grade of HPMC K4M in combination with carbopol slowed the release of calcium as compared with the formulation of low grade of HPMC K100LV with carbopol [29].

Based on the above results, the prepared in situ floating gel of F3 which showed $\mathrm{pH}$ 8.81, floating lag time of $131 \pm 0.09$, floating duration of $>12$ and viscosity $4730 \mathrm{cp}$ can be considered as the optimum formulation that met the aim of our work.

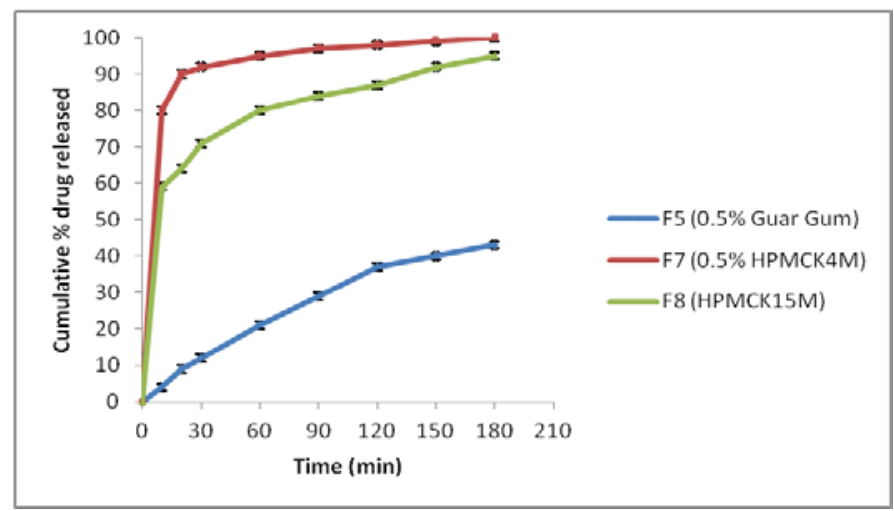

Fig. 4: Effect of viscosity enhancing polymers concentration on drug release (mean $\pm S D, n=3$ ) 


\section{CONCLUSION}

The enormous interest in studying the GDF was due to the ability of these formulations to stay in the stomach for a long time hence we focused in this work on the in situ gel formulation selecting the keto as a model. This was to study the capability of in situ gel formulation controlling the drug release and enhancing the solubility of keto in the stomach media. The results revealed that F1 showed $99 \%$ of keto released within 30 min which contained just $\mathrm{Na}$ alginate. Also, the reduction in $\mathrm{Na}$ alginate concentration in the presence of $0.5 \%$ $\mathrm{w} / \mathrm{w}$ GG from $2 \% \mathrm{w} / \mathrm{w}$ as in $\mathrm{F} 2$ to $1 \% \mathrm{w} /$ was in F3 led to increase the release of keto from $49 \%$ to $58 \%$ within 180 min respectively. Furthermore, it was found when the $\mathrm{CaCO}_{3}$ amount was reduced in $\mathrm{F} 3$ from $1 \% \mathrm{w} / \mathrm{w}$ to $0.5 \% \mathrm{w} / \mathrm{w}$ as in $\mathrm{F} 4$, the release of keto increased from $58 \%$ to $62 \%$. Additionally, the higher concentration of GG $1.5 \%$ $\mathrm{w} /$ win $\mathrm{F} 6$ showed a slower release to $40 \%$ of keto as compared with the lower concentration of $0.5 \% \mathrm{w} / \mathrm{w} \mathrm{GG}$ as in F5. Moreover, other than GG as viscosity enhancing agents, the addition of HPMC K4M effect was studied as in F7 which gave a higher release in comparison to the F8 that contained a higher grade the HPMCK $15 \mathrm{~K}$. Thus, the above different parameters showed the capability and feasibility to control the release of keto while the in situ gel formulation floating in the stomach.

\section{AKNOWLDGMENT}

The authors would like to express gratitude to Al-Mustansiriyah University (www. uomustansiriyh. edu. iq) Baghdad-Iraq for its support in the present work.

\section{AUTHORS CONTRIBUTIONS}

All the author have contributed equally

\section{CONFLICT OF INTERESTS}

\section{Declared none}

\section{REFERANCES}

1. Nayak AK, Malakar J, Sen KK. Gastroretentive drug delivery technologies: current approaches and future potential. J Pharm Educ Res 2010;1:1-12.

2. Lopesa CM, Bettencourta C, Rossib A, Francesca Buttinib F, Barataa P. Overview on gastroretentive drug delivery systems for improving drug bioavailability. Int J Pharm 2016;510:144-58.

3. Pawar VK, Kansa S, Garg G, Awasthi R, Singodia D, Giriraj T, et al. Gastroretentive dosage forms: a review with special emphasis on floating drug delivery systems. Drug Delivery 2011;18:97-110.

4. Bhardwaj L, Sharma PK, Malviya R. A short review on gastro retentive formulations for stomach specific drug delivery: special emphasis on floating in situ gel systems. Afr J Basic Appl Sci 2011;3:300-12.

5. Rajinikanth PS, Balasubramaniam J, Mishra B. Development and evaluation of a novel floating in situ gelling system of amoxicillin for eradication of Helicobacter pylori. Int J Pharm 2007;335:114-22.

6. Darekar AB, Patil VA, Gondkar SB, Saudagar RB. Development and characterization of novel in-situ floating gel of levocetirizine dihydrochloride for oral drug delivery system. Der Pharm Lett 2016;8:188-96.

7. Rosenfeld GC, Loose DS. Pharmacology $6^{\text {th }}$ ed. Lippincott Williams and Wilkins, a Wolters Kluwer business; 2014. p. 280.

8. Finkel, Richard, Clark, Michelle A, Cubeddu, Luigi X. Lippincott's illustrated reviews: pharmacology. $4^{\text {th }}$ ed. Lippincott Williams and Wilkins; 2009. p. 410.
9. Sweetman SS. Martindale: the complete drug refrance. $36^{\text {th }}$ ed. London: Pharmaceutical Press; 2009. p. 539.

10. Hasan MJ, Kamal BA. Formulation and evaluation of rantidine hydrochloride as floating in situ gel. Int J Pharm Pharm Sci 2014;6 Suppl2:401-5.

11. Prasad RaoMR, Shelar SU. Controlled release ion sensitive floating oral in situ gel of a prokinetic drug using gellan gum. Indian J Pharm Educ Res 2015;49:158-68.

12. Kubo W, Miyazaki S, Attwood D. Oral sustained delivery of paracetamol from In situ gelling gellan and sodium alginate formulations. Int J Pharm 2003;258:55-64.

13. Vipul V, Basu B. Formulation and characterization of novel floating in-situ gelling system for controlled delivery of ramipril. Int J Drug Delivery 2013;5:43-55.

14. Prasanthi S, Vidyavathim. Formulation and optimization of buoyant in situ gelling system of valsartan using natural polymer. Int J Pharm Pharm Sci 2017;9:128-36.

15. Thomas LM. Formulation and evaluation of floating oral in situ gel for metronidazole. Int J Pharm Pharm Sci 2014;6:265-9.

16. Jaafar IS. Formulation and in vitro evaluation of fast dissolving film of metoclopramide hydrochloride. Int J ChemTech Res 2017;10:26-38.

17. Rao M, Shelarl SU, Yunusil A. Controlled release floating oral in situ gel of itopride hydrochloride using $\mathrm{pH}$ sensitive polymer. Int J Pharm Pharm Sci 2014;6:338-43.

18. Hoi BY, Park HJ, Hwang SJ, Park JB. Preparation of alginate beads for floating drug delivery system: effect of $\mathrm{CO} 2$ gas forming agents. Int J Pharm 2002;239:81-91.

19. Kadivar A, Kamalidehghan B, Javar HA, Davoudi ET, Zaharuddin ND, Sabeti B, et al. Formulation and In vitro, in vivo evaluation of effervescent floating sustained-release imatinib mesylate tablet. PLOS One 2015;10:1-23.

20. TheUnited State Pharmacopeia (USP) 30, NF28, USA: The United State Pharmacopeial Convention Inc; 2010.

21. Singh BN, Kim KH. Floating drug delivery systems: an approach to oral controlled drug delivery via gastric retention. J Controlled Release 2000;63:235-59.

22. Varshosaz J, Tavakoli N, Roozbahani F. Formulation and in vitro characterization of ciprofloxacin floating and bioadhesive extended-release tablets. Drug Delivery 2006;13:277-85.

23. De Wit D, van Erp NP, Khosravan R, Wiltshire R, Allred R, Demetri GD, et al. Effect of gastrointestinal resection on sunitinib exposure in patients with GIST.BMC Cancer 2014;14:1-8.

24. Swathi G, Lakshmi PK. Design and optimization of hydrodynamically balanced oral in situ gel of glipizide. JAPS a 2015;5 Suppl 1:31-8.

25. Kumar KK, Swathi M, Srinivas L, Naseeb Basha S. Formulation and evaluation of floating in situ gelling system of losartan potassium. Der Pharm Lett 2015;7:98-112.

26. Rohith G, Sridhar BK, Srinatha A. Floating drug delivery of a locally acting H2-antagonist: An approach using an in situ gelling liquid formulation. Acta Pharm 2009;59:345-54.

27. Maheswaran A, Padmavathy J, Nadhini V, Saravanan D, Angel P. Formulation and evaluation of Floating oral in situ gel of diltiazem. Int J Appl Pharm 2017;9:50-3.

28. Nassoura L, Hasana I, El-Hammadia M, Abboudb H. Floating insitu-gelling gellan formulations of metformin hydrochloride. J Chem Pharm Res 2014:6:1509-17.

29. Li S, Lin S, Daggy BP, Mirchandani HL, Chien YW. Effect of HPMC and carbopol on the release and floating properties of gastric floating drug delivery system using factorial design. Int J Pharm 2003;253:13-22. 